\title{
Numerical Simulation of Creep Damage and Life Prediction of Superalloy Turbine Blade
}

\author{
Donghuan Liu, ${ }^{1}$ Haisheng $\mathrm{Li}^{2}{ }^{2}$ and Yinghua $\mathrm{Liu}^{3}$ \\ ${ }^{1}$ Department of Applied Mechanics, University of Science and Technology Beijing, Beijing 100083, China \\ ${ }^{2}$ National Center for Materials Service Safety, University of Science and Technology Beijing, Beijing 100083, China \\ ${ }^{3}$ School of Aerospace, Tsinghua University, Beijing 100084, China \\ Correspondence should be addressed to Yinghua Liu; yhliu@mail.tsinghua.edu.cn
}

Received 13 September 2014; Accepted 2 December 2014

Academic Editor: Chenfeng Li

Copyright (C) 2015 Donghuan Liu et al. This is an open access article distributed under the Creative Commons Attribution License, which permits unrestricted use, distribution, and reproduction in any medium, provided the original work is properly cited.

\begin{abstract}
Creep caused failure is an important failure mode of the turbine blade. A numerical approach of life assessment of the superalloy turbine blade is proposed in the present paper based on the Lemaitre-Chaboche creep damage model. Material damage is introduced into each element based on the ANSYS APDL function, and the creep damage effect is considered through the modification of Young's modulus. At last, the strength life and stiffness life of the blade can be obtained through the maximum damage and maximum creep strain criterion, respectively. The present method can not only consider the effect of creep damage, but also give the time histories of the element stresses, damage, and creep strain. The above life prediction results based on the proposed method are compared with the $\theta$ projection method, and the results suggest that the present life prediction method of turbine blade is feasible and turbine blade's life in the present study is determined by creep fracture rather than creep deformation.
\end{abstract}

\section{Introduction}

Creep failure is one of the most important failure modes of turbine blade. Creep is the progressive time-dependent inelastic deformation under mechanical load and high temperature. The creep process is accompanied by many different microstructural rearrangements including dislocation movement, aging of microstructure, and grain-boundary cavitation. Over the preceding decades, many numerical and experimental investigations have been performed to improve the knowledge of creep of structures under high temperature. Creep constitutive relationship, creep damage evolution equation, and creep life prediction method are three main topics.

Hayhurst et al. presented a methodology for accurately calibrating constitutive parameters for a $1 / 2 \mathrm{Cr}-1 / 2 \mathrm{Mo}-1 / 4 \mathrm{~V}$ ferritic steel. The accurate description achieved is attributed to the physical basis of the constitutive equations and particularly to the state variables that represents the coarsening of the carbide precipitates and the creep constrained cavity growth $[1,2]$. Hore and Ghosh developed a simple method of estimating material parameters for Dyson-McLean model [3]. Constitutive equations for time independent plasticity and creep of 316 stainless steel at $550^{\circ} \mathrm{C}$ were given by Hayhurst et al. [4]. Ma et al. presented a method for determining the power law creep constants using the small punch (SP) creep test [5]. The biggest advantage of SP creep test is that it can be used to evaluate remaining creep life using very small specimens extracted from in-service components. Saad et al. developed a material constitutive model for the P91 and the P92 steels under cyclic loading and high temperature conditions [6]. Bolton proposed a characteristic-strain model of creep of analyzing long term-relaxed stresses and creep strains in engineering components under steady load [7]. Bolton independently examined the worked example presented in BSI document PD6605-1:1998, to illustrate the selection, validation, and extrapolation of a creep rupture model using statistical analysis [8]. Wilshire and Scharning presented a new approach to analysis of stress rupture data allowing rationalization, extrapolation, and interpretation of multibatch creep life measurements reported for ferritic $1 \mathrm{Cr}-$ 0.5 Mo tube steel [9]. Holdsworth et al. reviewed results are 
of an ECCC work program to investigate procedures for the practical representation of mean creep behavior for wellspecified alloys from large multisource, multicast strain-time datasets. Leinster proposed a method of creep rupture data extrapolation based on physical processes [10].

Zhang et al. studied creep-fatigue interaction damage evolution of the nuclear engineering materials modified $9 \mathrm{Cr}-$ $1 \mathrm{Mo}$ steel with continuum damage mechanics (CDM) theory [11]. Wilshire and Burt interpreted normal creep curves in terms of the deformation mechanisms controlling strain accumulation and the damage processes causing tertiary acceleration and eventual failure [12]. Hyde et al. used single-state variable and three-state variable creep damage constitutive models to investigate the material behavior of two P91 steels of differing strength [13]. Spindler determined the material properties of some creep and constant strain rate tests on a Type 347 weld metal, and then various creep damage models are used to predict the creep damage in some creep-fatigue tests on the same Type 347 weld metal $[14,15]$. Guan et al. presented quantitative study of creep cavity area of HP40 furnace tubes [16]. Hyde et al. presented a novel modelling process for creep crack growth prediction of a 316 stainless steel using continuum damage mechanics, in conjunction with finite element (FE) analysis [17]. Smith et al. investigated the type IV creep cavity accumulation and failure in steel welds [18].

Mackerle reviewed the finite element methods applied to creep and creep fracture/damage of engineering materials and structures from the theoretical as well as practical points of view [19]. Masuyama interrupted large-size cross-weld creep rupture testing at given creep life fractions until rupture to measure the hardness, microstructure, and potential drop in the heat affected zones of welds to clarify creep degradation in welds of Mod.9Cr-1Mo steel [20]. Ling et al. performed several small punch creep tests on Type 304 stainless steel at $650^{\circ} \mathrm{C}$ and presented a finite element model with modified Kachanov-Rabotnov creep damage constitutive equations [21]. Izaki et al. proposed a residual creep life assessment method for boiler pipes using small punch creep (SPC) test [22]. Massé and Lejeail numerically investigated the creep behaviour and damage mechanisms of modified 9CrlMo steel between $450^{\circ} \mathrm{C}$ and $650^{\circ} \mathrm{C}[23,24]$. Weber et al. developed a method for creep life prediction for pipe bends with GrahamWallas creep law [25]. Oldham and Abou-Hanna presented a fast and effective method for creep-fatigue life prediction of 9Cr-1Mo (grade 91) for a temperature range of $500^{\circ} \mathrm{C}-550^{\circ} \mathrm{C}$ [26]. Oh et al. proposed a method to simulate creep failure using finite element damage analysis and the method was applied to simulate creep crack growth in six different types of cracked specimens of $316 \mathrm{H}$ at $550^{\circ} \mathrm{C}$. The creep damage model is based on the creep ductility exhaustion concept, and incremental damage is defined by the ratio of incremental creep strain and multiaxial creep ductility $[27,28]$. Yao et al. grouped the existing theories and creep design approaches into three categories, that is, the classical plastic theory (CPT) based approach, the cavity growth mechanism (CGM) based approach, and the continuum damage mechanics (CDM) based approach [29].
Beside these, many efforts are devoted to the life prediction of turbine blade. Lewis and Beckwith reviewed the life prediction approaches of the turbine blade [30]. Abu et al. provided a life assessment tool for aero jet engine blades by integrating suitable models and software with the Neu/Sehitoglu damage model [31]. Marahleh et al. predicted the operating life of service-exposed blades used in industrial gas turbines [32]. Chen et al. proposed a power-exponent function model for the life prediction of turbine blades under creep-fatigue interaction $[33,34]$. Rodríguez et al. developed artificial neural network (ANN) to predict the useful life (UL) of the blades [35]. Schönbauer et al. investigated the influence of corrosion pits on the endurable fatigue loading in different environments and at various stress ratios for $12 \%$ Cr steam turbine blade steel [36]. Tawancy and Al-Hadhrami compared the microstructural changes of unused and used blades in power generation [37].

Although many researches have conducted on the creep performance of the turbine blade, previous works always perform the finite element calculation through complex creep and damage relations with user subroutine. In the present research, a simple and feasible approach is proposed to investigate the creep life of turbine blade.

\section{Material Characterization}

This section gives the thermophysical parameters, creep constitutions, and creep damage evolution relationship of the turbine blade material GH4169. GH4169 is a domestic high temperature alloy, known as Inconel 718 in USA.

Thermal and mechanical properties such as thermal conductivity, specific heat, elastic modulus, Poisson's ratio, and thermal expansion coefficient are presented in Tables 1, 2, 3,4 , and 5 [38]. These parameters are temperature-dependent. Density of GH4169 is $8240 \mathrm{~kg} / \mathrm{m}^{3}$ and is assumed to be a constant.

The most important and widely used constitutive equation to predict the secondary creep is Norton's power law equation:

$$
\dot{\varepsilon}_{\text {cr }}=C_{1} \sigma^{C_{2}} \mathrm{e}^{-C_{3} / T}
$$

where $\dot{\varepsilon}_{\mathrm{cr}}$ is the steady state creep strain rate, $\sigma$ is stress (MPa), $T$ is temperature $(\mathrm{K}), C_{1}, C_{2}$, and $C_{3}$ are material constant which should be determined based on creep test data, and they are $C_{1}=2.147 \times 10^{-70.03}, C_{2}=10.171$, and $C_{3}=$ 50825.890, respectively [39].

Creep caused damage is also considered in the present research, and the damage evolution relationship is given by the modified Lemaitre-Chaboche model [40]:

$$
\frac{d D_{C}}{d t}=\left(\frac{\sigma}{A}\right)^{r}\left(1-D_{C}\right)^{-k},
$$

where $D_{C}$ is the creep damage, $t$ is time $(\mathrm{h}), \sigma$ is stress $(\mathrm{MPa})$, and $k$ is given by

$$
k=a_{0}+a_{1}(\sigma-z)+a_{2}(\sigma-z)^{2},
$$

where $r, A, a_{0}, a_{1}, a_{2}$, and $z$ are material constant which should be determined based on creep test data and are shown in Table 6 [41]. 
TABLE 1: Thermal conductivity of GH4169 with different temperatures.

\begin{tabular}{|c|c|c|c|c|c|c|c|c|c|c|}
\hline $\mathrm{T} /{ }^{\circ} \mathrm{C}$ & 100 & 200 & 300 & 400 & 500 & 600 & 700 & 800 & 900 & 1000 \\
\hline$\lambda /\left(\mathrm{W} /\left(\mathrm{m} \cdot{ }^{\circ} \mathrm{C}\right)\right)$ & 14.7 & 15.9 & 17.8 & 18.3 & 19.6 & 21.2 & 22.8 & 23.6 & 27.6 & 30.4 \\
\hline
\end{tabular}

TABLE 2: Specific heat of GH4169 with different temperatures.

\begin{tabular}{lllllllll}
\hline $\mathrm{T} /{ }^{\circ} \mathrm{C}$ & 300 & 400 & 500 & 600 & 700 & 800 & 900 & 1000
\end{tabular}

$\begin{array}{lllllllll}\mathrm{C} /\left(\mathrm{J} /\left(\mathrm{kg} .{ }^{\circ} \mathrm{C}\right)\right) & 481.4 & 493.9 & 514.8 & 539 & 573.4 & 615.3 & 657.2 & 707.4\end{array}$

TABLE 3: Elastic modulus of GH4169 with different temperatures.

\begin{tabular}{lccccc}
\hline$T /{ }^{\circ} \mathrm{C}$ & 25 & 400 & 500 & 650 & 750 \\
\hline $\mathrm{E} / \mathrm{GPa}$ & 205 & 175.5 & 168.5 & 142 & 130.5 \\
\hline
\end{tabular}

TABLE 4: Poisson's ratio of GH4169 with different temperatures.

\begin{tabular}{cccccccc}
\hline$T /{ }^{\circ} \mathrm{C}$ & 25 & 300 & 400 & 500 & 600 & 650 & 750 \\
\hline$\mu$ & 0.321 & 0.329 & 0.339 & 0.344 & 0.355 & 0.361 & 0.381 \\
\hline
\end{tabular}

It should be noted that as (2) is nonlinear, the computation of the damage is an iterative process.

\section{Thermomechanical Analysis}

In the present research, $E^{3}$ (energy efficient engine) high pressure turbine blade is employed based on the airfoil profile published by NASA [42]. Geometry of the turbine blade is firstly created in CAD software and then imported into ANSYS, which is shown in Figure 1. The model details at top and bottom of the blade are ignored in the present research; at the same time, the bottom of the blade is extended to simulate the effect of the tongue and groove.

3.1. Thermal Analysis. Thermal analysis should be conducted to obtain the temperature field of the turbine blade. 3D fluid thermal analysis is performed in the present analysis with FLUENT. The basic equations for fluid dynamics are as follows [43].

(1) Continuity Equation. Continuity equation is also called the conservation of mass, which ensures that the total mass is conserved; in other words, the total mass of a fluid system is completely accounted for. In three dimensions, the continuity equation is

$$
\frac{\partial \rho}{\partial t}+\nabla \cdot(\rho \mathbf{u})=0
$$

where $\rho$ is the density, $t$ is time, $\mathbf{u}$ is the velocity vector, and $\nabla$ is the gradient operator.

(2) Momentum Conservation Equation. The principal of conservation of linear momentum means the total force generated by the momentum transfer in each direction

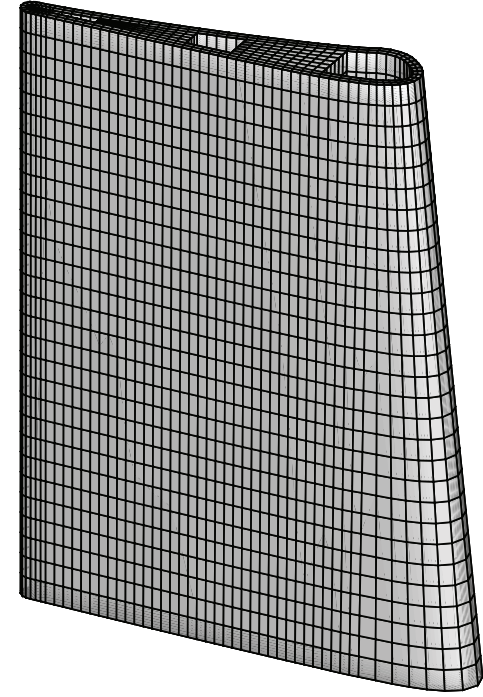

FIgURE 1: Finite element discretization of the turbine blade.

is balanced by the rate of change of momentum in each direction and is given by

$$
\rho\left(\frac{\partial \mathbf{u}}{\partial t}+\mathbf{u} \cdot \nabla \mathbf{u}\right)=\nabla \cdot \boldsymbol{\sigma}+\rho \mathbf{f}
$$

where $\mathbf{f}$ is the body force vector and $\boldsymbol{\sigma}$ is the Cauchy stress tensor and is defined by

$$
\boldsymbol{\sigma}=\mu\left(\nabla \mathbf{u}+(\nabla \mathbf{u})^{T}\right)-p \mathbf{I}
$$

where $\mu$ is the shear viscosity of fluid, superscript " $T$ " means transpose, $p$ is pressure, and $\mathbf{I}$ is the identity matrix.

(3) Energy Conservation Equation. The energy balance can be obtained as heat entering the control volume by convection and heat entering the control volume by diffusion are equal to heat exiting the control volume by convection and heat exiting the control volume by diffusion and rate of change of energy within the control volume. Energy conservation equation is given by

$$
\rho C_{p}\left(\frac{\partial T}{\partial t}+\mathbf{u} \cdot \nabla T\right)=-\nabla \cdot \mathbf{q}+Q
$$

where $C_{p}$ is heat capacity, $T$ is temperature, $\mathbf{q}$ is the heat flux vector, and $Q$ is the internal heat generation.

(4) Turbulent Flow Equation. Turbulent $k-\varepsilon$ is widely used in engineering practice to study turbulent flow, and 
TABLE 5: Thermal expansion coefficient of GH4169 with different temperatures.

\begin{tabular}{|c|c|c|c|c|c|c|c|c|c|c|}
\hline$T /{ }^{\circ} \mathrm{C}$ & 100 & 200 & 300 & 400 & 500 & 600 & 700 & 800 & 900 & 1000 \\
\hline$\alpha /\left(10^{-6 \circ} \mathrm{C}^{-1}\right)$ & 11.8 & 13.0 & 13.5 & 14.1 & 14.4 & 14.8 & 15.4 & 17 & 18.4 & 18.7 \\
\hline
\end{tabular}

TABLE 6: Thermal expansion coefficient of GH4169 with different temperatures.

\begin{tabular}{lcccccc}
\hline Parameter & $r$ & $A$ & $z$ & $a_{0}$ & $a_{1}$ & $a_{2}$ \\
\hline Value & 13.19 & 1209 & 733.25 & 13.2478 & $0.7865 \times 10^{-4}$ & $0.1924 \times 10^{-3}$ \\
\hline
\end{tabular}

the turbulent kinetic $k$ equation and turbulent dissipation $\varepsilon$ equation are given, respectively, by

$$
\begin{gathered}
\frac{\partial(\rho k)}{\partial t}+\nabla \cdot(\rho \mathbf{u} k)=\nabla \cdot\left(\left(\mu+\frac{\mu_{t}}{\sigma_{k}}\right) \nabla k\right)-\rho \varepsilon+\mu_{t} P_{G} \\
\frac{\partial(\rho \varepsilon)}{\partial t}+\nabla \cdot(\rho \mathbf{u} \varepsilon)=\nabla \cdot\left(\left(\mu+\frac{\mu_{t}}{\sigma_{\varepsilon}}\right) \nabla \varepsilon\right) \\
-\rho C_{2} \frac{\varepsilon^{2}}{k}+\mu_{t} C_{1} \frac{\varepsilon}{k} P_{G}
\end{gathered}
$$

where turbulent viscosity coefficient $\mu_{t}$ and turbulent kinetic generation term $P_{G}$ satisfied

$$
\begin{gathered}
\mu_{t}=\rho C_{\mu} \frac{k^{2}}{\varepsilon} \\
P_{G}=2\left[\left(\frac{\partial u}{\partial x}\right)^{2}+\left(\frac{\partial v}{\partial y}\right)^{2}+\left(\frac{\partial w}{\partial z}\right)^{2}\right] \\
+\left(\frac{\partial u}{\partial y}+\frac{\partial v}{\partial x}\right)^{2}+\left(\frac{\partial u}{\partial z}+\frac{\partial w}{\partial x}\right)^{2}+\left(\frac{\partial v}{\partial z}+\frac{\partial w}{\partial y}\right)^{2},
\end{gathered}
$$

where $k$ is turbulent kinetic energy, $\varepsilon$ is the turbulent dissipation rate, and $\mu_{t}, \sigma_{k}, \sigma_{\varepsilon}, C_{1}, C_{2}$, and $C_{\mu}$ are constant.

The fluid heat transfer analysis is conducted with FLUENT after importing the finite element model from ANSYS.

Convective heat transfer boundary is applied at the inner surface of the cooling channel of the turbine blade, and the convective heat transfer coefficient and wall temperature are assumed to be $400 \mathrm{~W} / \mathrm{m}^{2} \mathrm{~K}$ and $600 \mathrm{~K}$, respectively. The inlet pressure is $1.324 \mathrm{MPa}$ and the inlet temperature is $1633 \mathrm{~K}$. Temperature field of the turbine blade is given in Figure 2.

It can be seen from Figure 3 that the temperature is ranging from $770 \mathrm{~K}$ to $920 \mathrm{~K}$, and the maximal temperature is about $920 \mathrm{~K}$ at the bottom of the leading edge. In general, when temperature is larger than 0.3 times of the melt point, creep will become important, and the melt point of GH4169 is about $1533 \mathrm{~K}$, which means creep plays a very important role in the life prediction of the turbine blade.

3.2. Mechanical Analysis. There are different sources of loads imposed on the turbine blade. Due to the rotation, the blade is

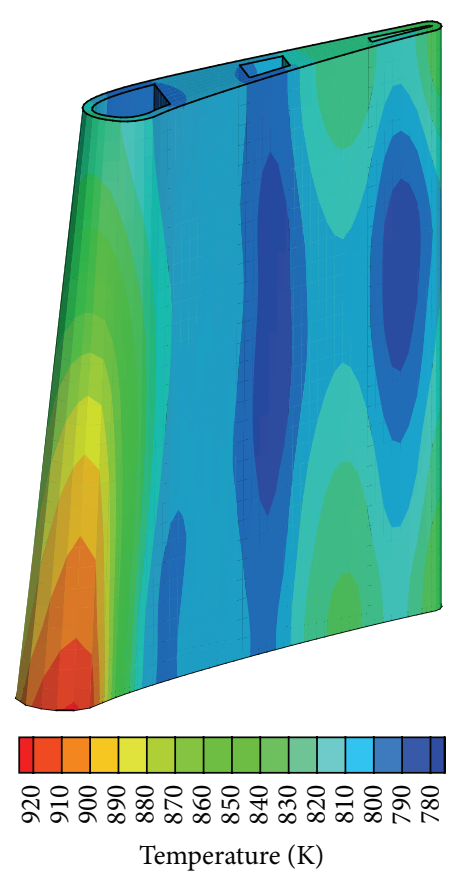

FIGURE 2: Temperature field of the turbine blade.

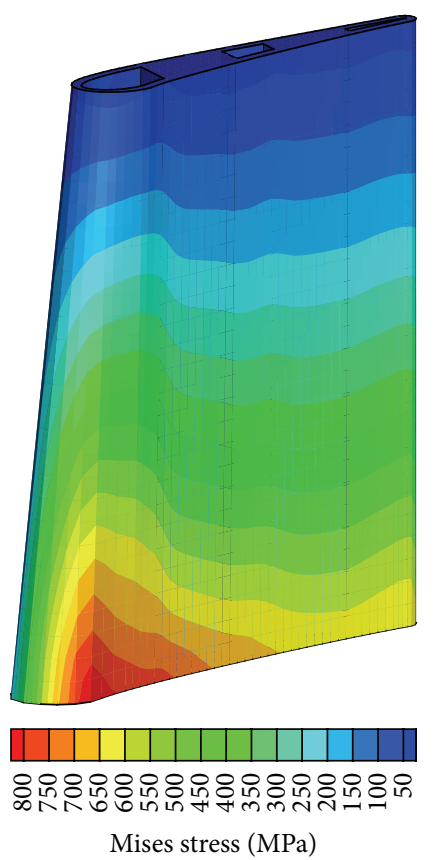

FIgURE 3: Equivalent stress field of the turbine blade under inertial force. 


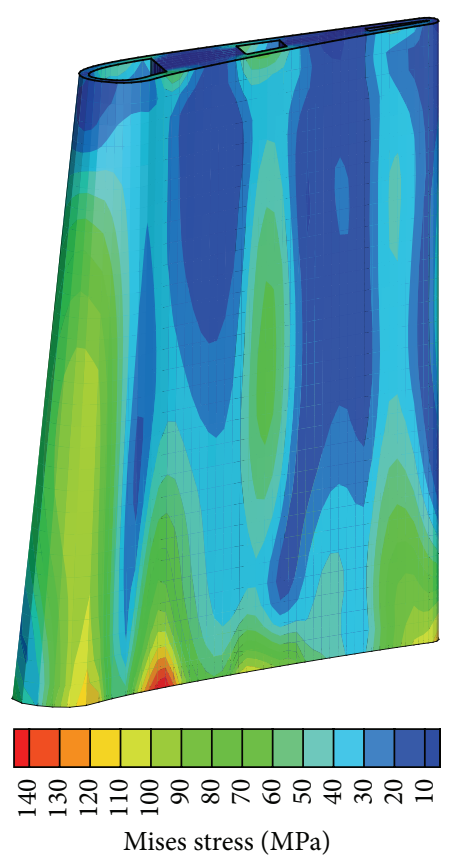

Figure 4: Equivalent stress field of the turbine blade under temperature.

subjected to inertial force which acts along the axial direction, and the angular velocity of the blade is $13223 \mathrm{rpm}$. Aerodynamic pressure is not considered in the present research. Temperature field obtained in the previous section is applied on the finite element node as body forces. The computation is conducted with ANSYS, and SOLID185 element with hexahedron mesh is used. There are 11026 meshes and 14630 nodes. Three load cases are calculated; only inertial force, only temperature, both inertial force and temperature, and the equivalent stress field of the turbine blade under these three conditions are shown in Figures 3, 4, and 5, respectively.

It can be seen from Figures 3-5 that, under individual inertial force and temperature, the maximal equivalent stress of the turbine blade is $800 \mathrm{MPa}$ and $140 \mathrm{MPa}$ respectively, while with the consideration of both inertial force and temperature, the maximal equivalent stress is $850 \mathrm{MPa}$. It is found that inertial force is the primary source of the blade stress, and thermal stress is secondary. The main effect of the temperature is that of activation of the creep process.

\section{Creep Life Prediction}

4.1. Computational Flowchart. Equations (1) and (2) are implemented within ANSYS in the present research. With the development of the creep process, the stress is relaxed and becomes smaller, while creep damage becomes larger. As damage is affected by stress and temperature, which is quite different from element to element, creep in each element is different. In the present research, effect of damage to the blade is realized by changing Young's modulus of the material:

$$
E=E_{0}\left(1-D_{C}\right),
$$

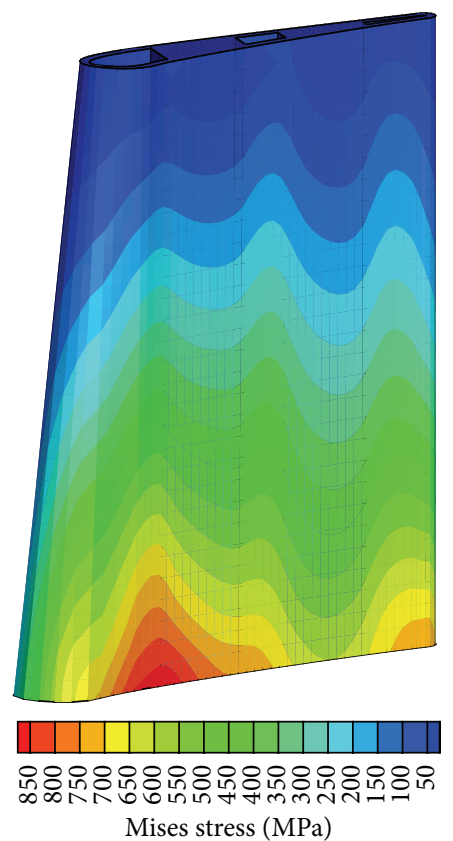

FIGURE 5: Equivalent stress field of the turbine blade under both inertial force and temperature.

where $E$ is present Young's modulus and $E_{0}$ is original Young's modulus. It is noted that even original Young's modulus of each element is different as the temperature of each element is different.

The computations are conducted by the following steps.

Step 1. Import CAD model of the turbine blade into ANSYS.

Step 2. Mesh the turbine blade and assign every element with different material number.

Step 3. Import finite element model into FLUENT and perform the fluid heat transfer computation to obtain the heat flux field of the outer surface of the turbine blade.

Step 4. Import the heat flux field of the outer surface of the turbine blade obtained in Step 3 and apply boundary conditions at the surface of the cooling channel and then perform the heat transfer computation to obtain the temperature field of the turbine blade.

Step 5. Switch element type from thermal analysis to structural analysis and apply node temperature obtained in Step 4 as body force and structural boundary conditions and inertial force. Initialize the damage of each element.

Step 6. Begin computation and give displacement, stress, and strain.

Step 7. Compute element damage with (2).

Step 8. Evaluate the safety of the turbine blade with failure criterion. If the turbine blade is failed, the present time will 


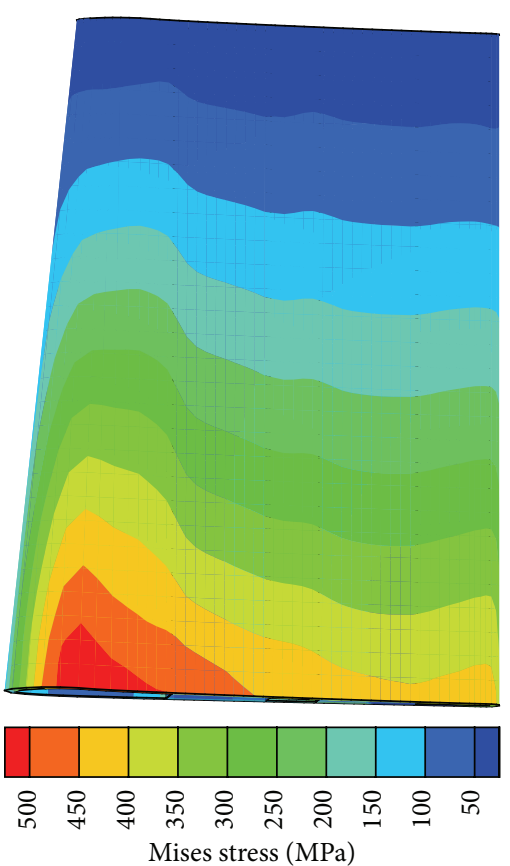

FIGURE 6: Equivalent stress of the turbine blade after creep $441 \mathrm{~h}$.

be the lifetime of the turbine blade. If not, modify Young's modulus of each element with element damage obtained in Step 7 and then turn to Step 6 to perform computation of the next time step.

Two-creep failure criterion is considered in the present research, one is creep rupture when the maximum damage of the structure reaches a threshold value, and the other is creep deformation failure when the creep strain or creep deformation reaches a threshold value. In the present paper, lifetime based on these two failure modes is called strength lifetime and stiffness lifetime, respectively, since the gap between the rotor and stator is usually less than $1 / 1000$ of the rotational radius of the blade to prevent or reduce the gas leakage through the blade tip-gap.

Load and boundary conditions in creep analysis are the same as in the mechanical analysis, and during the whole computation these conditions are assumed to be constant.

4.2. Strength Lifetime. In the present research, threshold value of element damage is defined by $D_{C}=0.4$, as the remaining creep time before complete failure occurs is very small compared to the total creep time. Time when the maximal element damage reaches 0.4 is defined as the strength lifetime of the turbine blade. It is found that the strength lifetime of the turbine blade in the present research is $441 \mathrm{~h}$, with a maximal element damage of 0.415 . After creep for $441 \mathrm{~h}$, the equivalent stress and element damage of the turbine blade are shown in Figures 6 and 7, respectively. Figures 8 and 9 give the evolution of the maximal element damage and maximal equivalent stress.

Compared with Figures 5 and 6, it can be found that after creep for $441 \mathrm{~h}$, the maximal equivalent stress decreases from

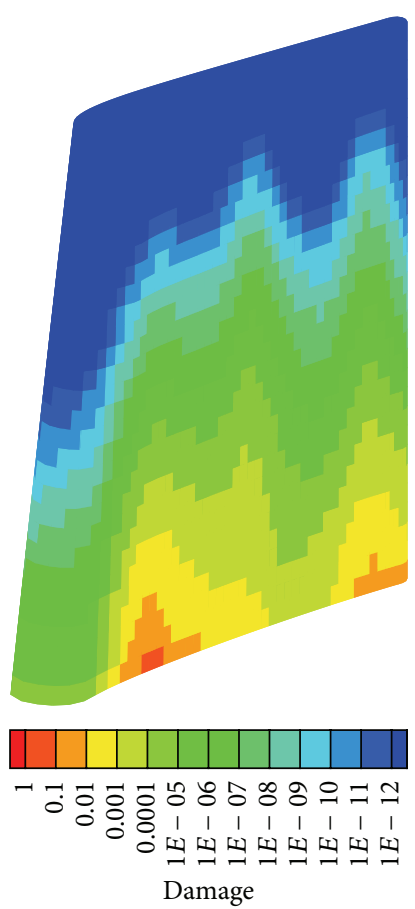

Figure 7: Element damage of the turbine blade after creep $441 \mathrm{~h}$.

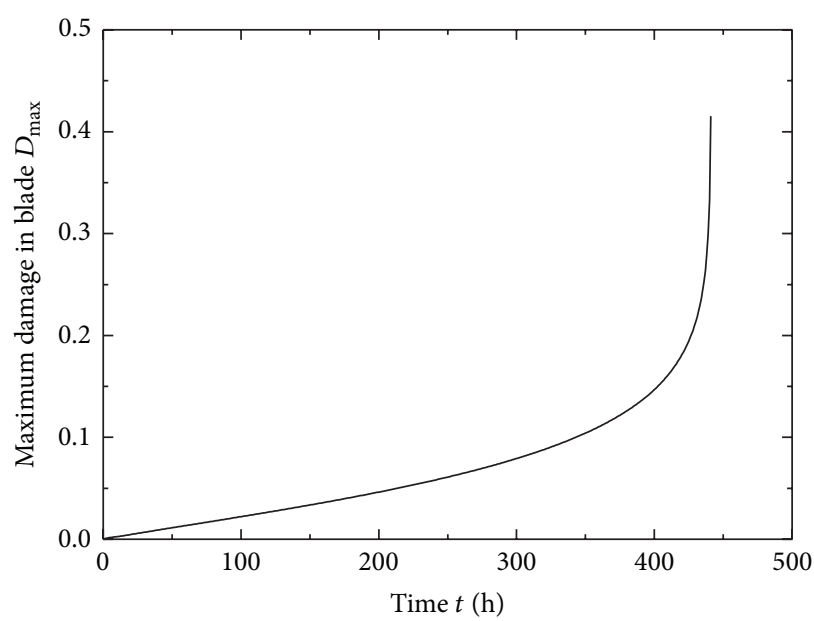

FIgURE 8: Evolution of the maximal element damage.

$800 \mathrm{MPa}$ to $558 \mathrm{MPa}$. It can be seen from Figure 7 that the maximal element damage locates at the area that maximal stress exists, this is, because the damage is primarily affected by the stress as shown in (2). The evolution of the maximal element damage shown in Figure 8 reveals that the maximal element damage increases linearly at the first and second creep stages and then at the third stage, damage increases rapidly until rupture. Figure 9 shows the relaxation of the maximal equivalent stress; it is very clear that stress decreases rapidly at the very beginning and after a very short time, stress begins the steady relaxation until the end of the creep when stress decreases rapidly to fracture. 


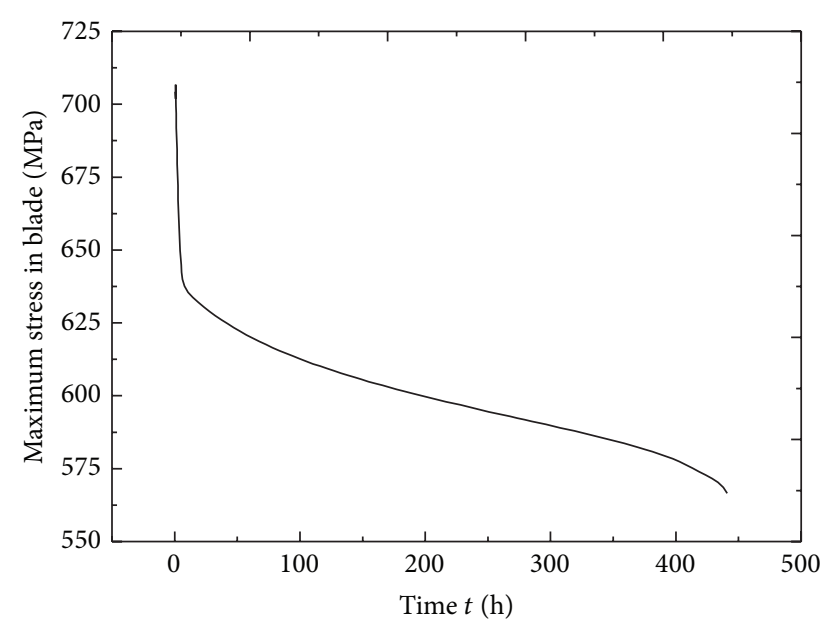

FIGURE 9: Evolution of the maximal equivalent stress.

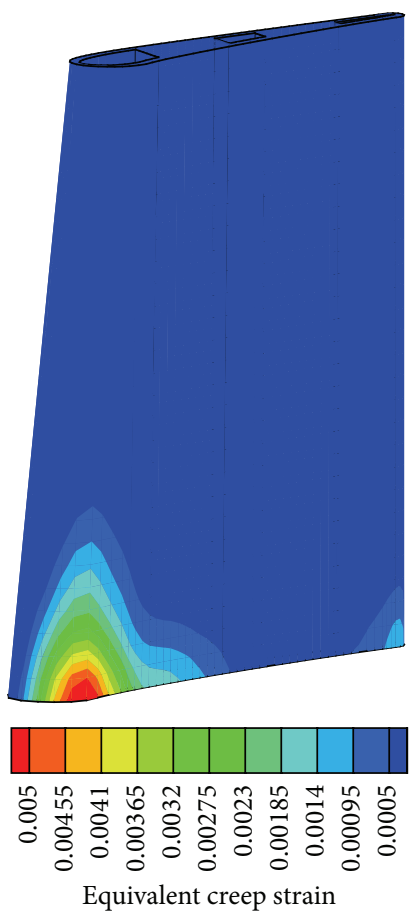

FIGURE 10: Creep strain of the turbine blade after creep $443 \mathrm{~h}$.

4.3. Stiffness Lifetime. In the present research, threshold value of creep strain is defined by $\varepsilon_{\mathrm{cr}}=1 \%$ [44]. Figures 10 and 11 show the creep strain field of the turbine blade after creeps $433 \mathrm{~h}$ and $855 \mathrm{~h}$, respectively.

It can be seen from Figures 10 and 11 that, after creep $443 \mathrm{~h}$, the maximal creep strain of the turbine blade is $0.5997 \%$, and it is smaller than the threshold value and the threshold value is reached at $856 \mathrm{~h}$ with the maximal creep strain $1.07 \%$, which means the stiffness lifetime of the turbine blade is $856 \mathrm{~h}$. Compared with the strength lifetime and stiffness lifetime, it is found that strength lifetime is much smaller than the stiffness lifetime which means that

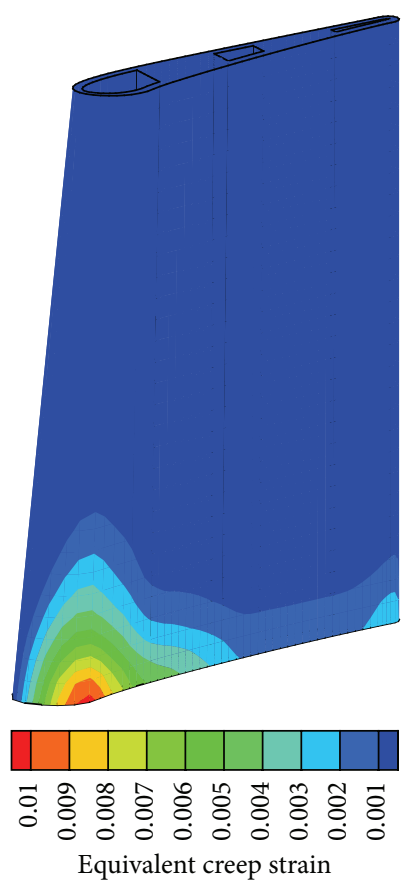

FIGURE 11: Creep strain of the turbine blade after creep $856 \mathrm{~h}$.

the turbine blade may be broken before too much deformation exists.

\section{Comparisons with $\theta$ Projection Method}

$\theta$ projection method is a widely used method in the lifetime prediction of high temperature structures. It is proposed by UK's National Physical Laboratory [45], and this method assumed that the creep strain can be given by

$$
\varepsilon_{c}=\varepsilon_{0}+\theta_{1}\left(1-\mathrm{e}^{\left(-\theta_{2} t\right)}\right)+\theta_{3}\left(\mathrm{e}^{\left(\theta_{4} t\right)}-1\right)
$$

where $\varepsilon_{c}$ is the creep strain, $\varepsilon_{0}$ is the initial strain before creep occurs, and $t$ is time. $\theta_{1}\left(1-\mathrm{e}^{\left(-\theta_{2} t\right)}\right)$ and $\theta_{3}\left(\mathrm{e}^{\left(\theta_{4} t\right)}-1\right)$ represent the creep at the first stage and the third stage, respectively. $\theta_{i}(i=1,2,3,4)$ are experimentally determined constants, and they should satisfy

$$
\log \theta_{i}=a_{i}+b_{i} T+c_{i} \sigma+d_{i} \sigma T
$$

where $T$ is temperature and $\sigma$ is stress. $a_{i}, b_{i}, c_{i}$, and $d_{i}$ are material constant, once they are obtained and $\theta_{i}$ under any temperature and stress can be determined by (12), and the creep strain can be obtained by (11); then the creep lifetime of the structure will be obtained.

Based on the experimental results of GH4169 [46], $\theta_{i}(i=$ $1,2,3,4)$ are firstly determined and given in Table 7 . Then $a_{i}$, $b_{i}, c_{i}$, and $d_{i}$ can be determined by data fitting with (12), and they are given in Table 8. Comparisons of experimental data [46] and fitting data are shown in Figures 12, 13, and 14, and 15.

It is found that the fitting data compare very well with the experimental results, so the $\theta$ projection method can be used 
TABle 7: Parameters of $\theta_{i}$ with different temperature and stress.

\begin{tabular}{lccccc}
\hline Temperature $/{ }^{\circ} \mathrm{C}$ & Stress $/ \mathrm{MPa}$ & $\theta_{1}$ & $\theta_{2}$ & $\theta_{3}$ \\
\hline 600 & 740 & 0.010296 & 0.284201 & $2.093486 \times 10^{-6}$ & 0.172685 \\
650 & 750 & 0.013662 & 0.030494 & $2.421462 \times 10^{-7}$ & 0.086381 \\
660 & 700 & 0.016081 & 0.019141 & $6.367507 \times 10^{-6}$ & 0.066379 \\
670 & 700 & 0.007818 & 0.083223 & $1.419716 \times 10^{-4}$ & 0.066127 \\
\hline
\end{tabular}

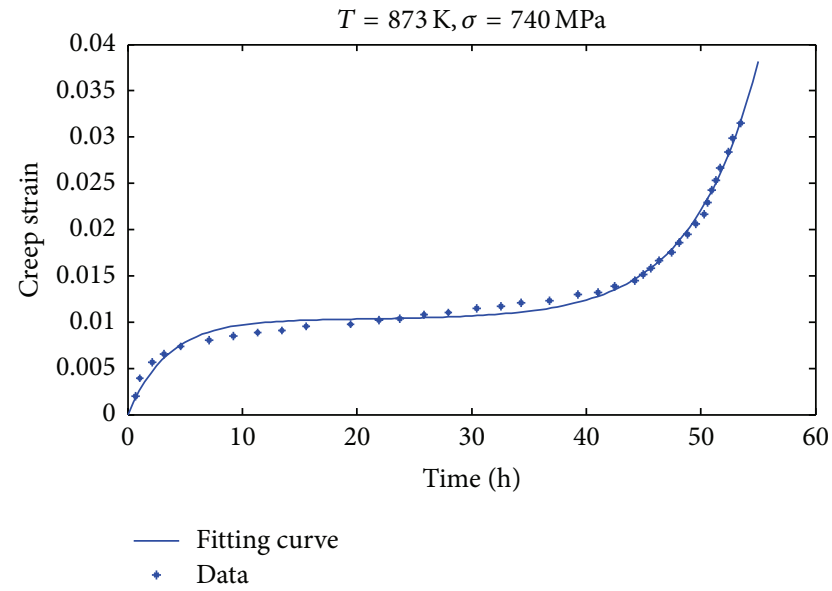

FIGURE 12: Comparisons of experimental data [46] and fitting data under $873 \mathrm{~K}$ and $740 \mathrm{MPa}$.

TABLE 8: Parameters of $a_{i}, b_{i}, c_{i}$, and $d_{i}$ with different $\theta_{i}$.

\begin{tabular}{lcccc}
\hline Parameter & $a_{i}$ & $b_{i}$ & $c_{i}$ & $d_{i}$ \\
\hline$\theta_{1}$ & 425.933468 & -0.649289 & -0.581509 & 0.000883 \\
$\theta_{2}$ & -1040.439613 & 1.578947 & 1.423707 & -0.002164 \\
$\theta_{3}$ & -1836.649917 & 2.817091 & 2.489243 & -0.003832 \\
$\theta_{4}$ & -74.340425 & 0.110132 & 0.104673 & -0.000157 \\
\hline
\end{tabular}

to predict the creep lifetime of the GH4169 turbine blade. As shown in Section 3, the temperature and stress of the hot point of the turbine blade are $804 \mathrm{~K}$ and $699 \mathrm{MPa}$, respectively; substituting these two values in (12), $\theta_{i}(i=1,2,3,4)$ can be obtained. Then substituting $\theta_{i}(i=1,2,3,4)$ into (11) and assigns $\varepsilon_{c}=1 \%, \varepsilon_{0}=0$, we can obtain the lifetime of the turbine blade with the $\theta$ projection method, which is $729.5 \mathrm{~h}$, and this value compared well with the stiffness lifetime $(856 \mathrm{~h})$ by direct simulation. This comparison also shows the feasibility of the present numerical approach.

\section{Conclusions}

A numerical approach of lifetime prediction of the turbine blade with creep damage is proposed in the present paper and then applied to the lifetime prediction of high pressure turbine blade. The present approach can directly give the evolution of element stress, creep deformation, and element damage, which is very useful in the life prediction of high temperature structures. Lifetime of the turbine blade with two different creep failure criterions, as well as the $\theta$ projection method, is given. Numerical results show that the present

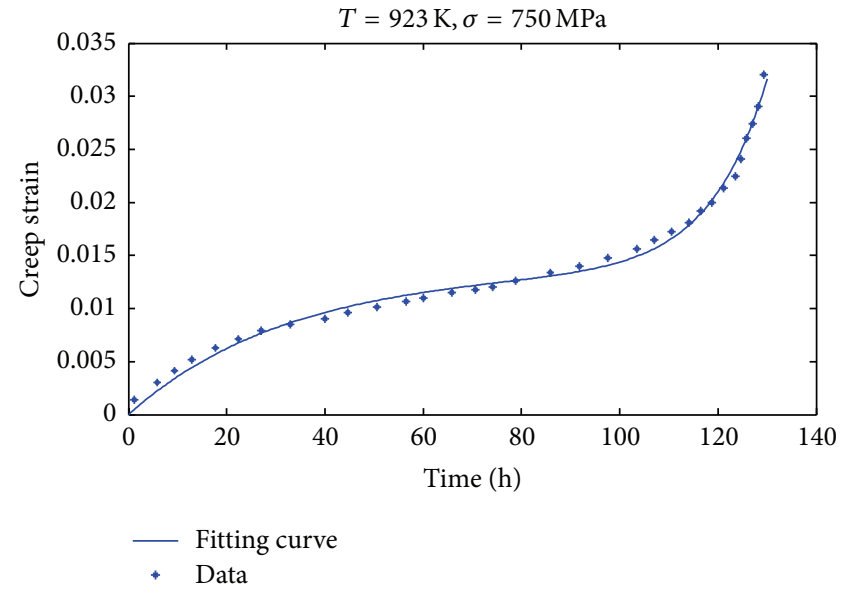

FIGURE 13: Comparisons of experimental data [46] and fitting data under $923 \mathrm{~K}$ and $750 \mathrm{MPa}$.

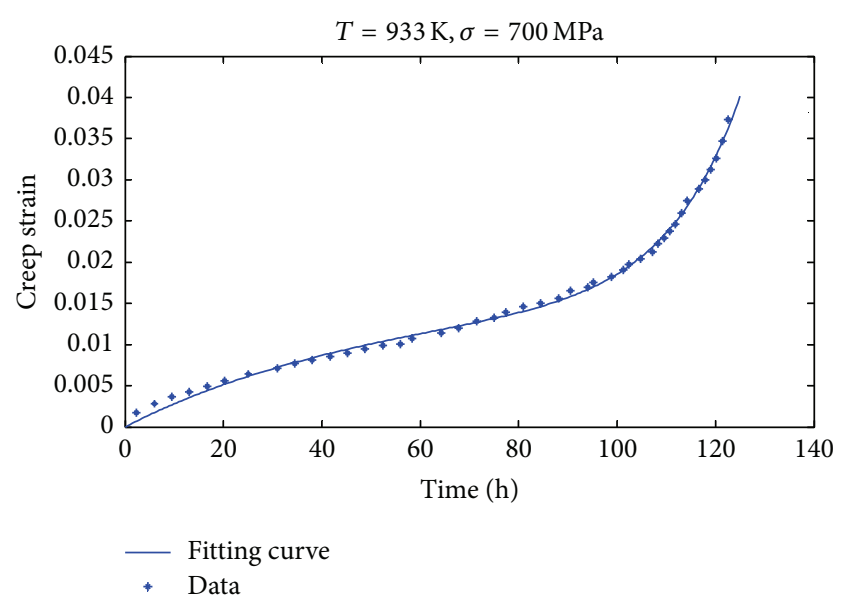

FIGURE 14: Comparisons of experimental data [46] and fitting data under $933 \mathrm{~K}$ and $700 \mathrm{MPa}$.

numerical approach based on creep damage for lifetime prediction of high temperature structure is feasible and reliable and provides a technical support for high temperature structure safety evaluation and design. With the creep failure criterion of creep rupture and creep deformation failure, the lifetime of the turbine blade is $441 \mathrm{~h}$ and $856 \mathrm{~h}$, respectively, and lifetime with $\theta$ projection method also based on creep deformation criterion is $729.5 \mathrm{~h}$. The difference of the lifetime with different failure criterion shows different failure mechanism, and it is found that turbine blade failure is mainly 


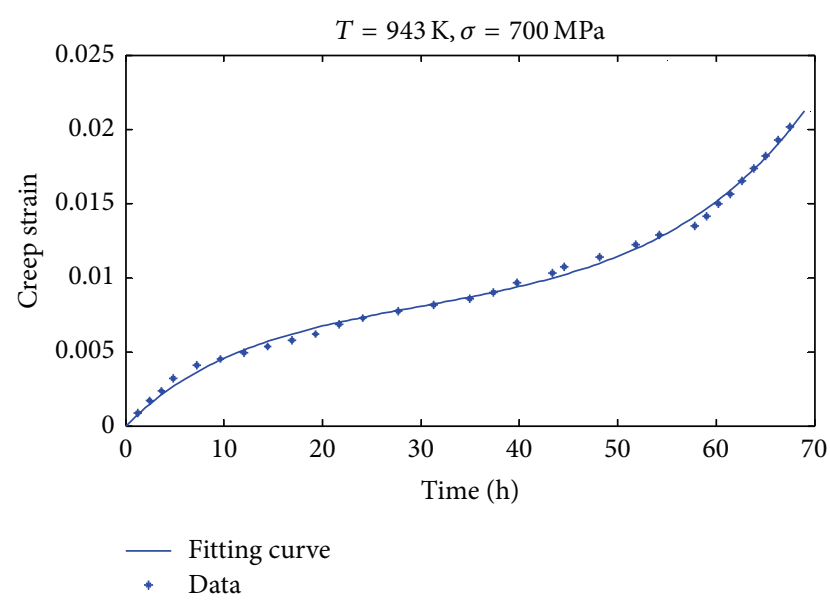

Figure 15: Comparisons of experimental data [46] and fitting data under $943 \mathrm{~K}$ and $700 \mathrm{MPa}$.

caused by creep rupture; in other words, the blade may be broken before the creep deformation reaches its limitation.

The present paper provides an alternative method to predict high temperature structure lifetime with creep damage, and future work should consider the effect of the interaction of creep and fatigue. Meanwhile, the present paper just shows the application of the present method in GH4169 and the application of the present method in other superalloys is also interesting.

\section{Conflict of Interests}

The authors declare that there is no conflict of interests regarding the publication of this paper.

\section{Acknowledgments}

This project is supported by the National High Technology Research and Development Program of China (Grant no. 2012AA03A513), the National Science Foundation for Distinguished Young Scholars of China (Project no. 11325211), National Natural Science Foundation of China (Project no. 11302023), and Fundamental Research Funds for the Central Universities (Project no. FRF-TP-14-030A1).

\section{References}

[1] R. Mustata and D. R. Hayhurst, "Creep constitutive equations for a $0.5 \mathrm{Cr} 0.5 \mathrm{Mo} 0.25 \mathrm{~V}$ ferritic steel in the temperature range $565^{\circ} \mathrm{C}-675^{\circ} \mathrm{C}$," International Journal of Pressure Vessels and Piping, vol. 82, no. 5, pp. 363-372, 2005.

[2] R. J. Hayhurst, R. Mustata, and D. R. Hayhurst, "Creep constitutive equations for parent, Type IV, R-HAZ, CG-HAZ and weld material in the range $565-640^{\circ} \mathrm{C}$ for $\mathrm{Cr}-\mathrm{Mo}-\mathrm{V}$ weldments," International Journal of Pressure Vessels and Piping, vol. 82, no. 2, pp. 137-144, 2005.

[3] S. Hore and R. N. Ghosh, "Computer simulation of the high temperature creep behaviour of Cr-Mo steels," Materials Science and Engineering A, vol. 528, no. 19-20, pp. 6095-6102, 2011.
[4] D. R. Hayhurst, F. Vakili-Tahami, and J. Q. Zhou, "Constitutive equation for time independent plasticity and creep of 316 stainless steel at $550^{\circ} \mathrm{C}$," International Journal of Pressure Vessels and Piping, vol. 80, no. 2, pp. 97-109, 2003.

[5] Y. W. Ma, S. Shim, and K. B. Yoon, "Assessment of power law creep constants of Gr91 steel using small punch creep tests," Fatigue \& Fracture of Engineering Materials \& Structures, vol. 32, no. 12, pp. 951-960, 2009.

[6] A. A. Saad, T. H. Hyde, W. Sun, C. J. Hyde, and D. W. J. Tanner, "Characterization of viscoplasticity behaviour of P91 and P92 power plant steels," International Journal of Pressure Vessels and Piping, vol. 111-112, pp. 246-252, 2013.

[7] J. Bolton, "Analysis of structures based on a characteristic-strain model of creep," International Journal of Pressure Vessels and Piping, vol. 85, no. 1-2, pp. 108-116, 2008.

[8] J. Bolton, "The extrapolation of creep rupture data by PD6605an independent case study," International Journal of Pressure Vessels and Piping, vol. 88, no. 4, pp. 158-165, 2011.

[9] B. Wilshire and P. J. Scharning, "Extrapolation of creep life data for 1Cr-0.5Mo steel," International Journal of Pressure Vessels and Piping, vol. 85, no. 10, pp. 739-743, 2008.

[10] M. G. Leinster, "A method of creep rupture data extrapolation based on physical processes," International Journal of Pressure Vessels and Piping, vol. 85, no. 10, pp. 701-710, 2008.

[11] G. Zhang, Y. Zhao, F. Xue et al., "Creep-fatigue interaction damage model and its application in modified 9Cr-1Mo steel," Nuclear Engineering and Design, vol. 241, no. 12, pp. 4856-4861, 2011.

[12] B. Wilshire and H. Burt, "Damage evolution during creep of steels," International Journal of Pressure Vessels and Piping, vol. 85, no. 1-2, pp. 47-54, 2008.

[13] T. H. Hyde, A. A. Becker, W. Sun, and J. A. Williams, "Finiteelement creep damage analyses of P91 pipes," International Journal of Pressure Vessels and Piping, vol. 83, no. 11-12, pp. 853863, 2006.

[14] M. W. Spindler, "The prediction of creep damage in type 347 weld metal. Part I: the determination of material properties from creep and tensile tests," International Journal of Pressure Vessels and Piping, vol. 82, no. 3, pp. 175-184, 2005.

[15] M. W. Spindler, "The prediction of creep damage in Type 347 weld metal: part II creep fatigue tests," International Journal of Pressure Vessels and Piping, vol. 82, no. 3, pp. 185-194, 2005.

[16] K. Guan, H. Xu, and Z. Wang, "Quantitative study of creep cavity area of HP40 furnace tubes," Nuclear Engineering and Design, vol. 235, no. 14, pp. 1447-1456, 2005.

[17] C. J. Hyde, T. H. Hyde, W. Sun, and A. A. Becker, "Damage mechanics based predictions of creep crack growth in 316 stainless steel," Engineering Fracture Mechanics, vol. 77, no. 12, pp. 2385-2402, 2010.

[18] D. J. Smith, N. S. Walker, and S. T. Kimmins, "Type IV creep cavity accumulation and failure in steel welds," International Journal of Pressure Vessels and Piping, vol. 80, no. 9, pp. 617-627, 2003.

[19] J. Mackerle, "Creep and creep fracture/damage finite element modelling of engineering materials and structures: an addendum," International Journal of Pressure Vessels and Piping, vol. 81, no. 5, pp. 381-392, 2004.

[20] F. Masuyama, "Creep degradation in welds of Mod.9Cr-1Mo steel," International Journal of Pressure Vessels and Piping, vol. 83, no. 11-12, pp. 819-825, 2006. 
[21] X. Ling, Y. Zheng, Y. You, and Y. Chen, "Creep damage in small punch creep specimens of Type 304 stainless steel," International Journal of Pressure Vessels and Piping, vol. 84, no. 5, pp. 304-309, 2007.

[22] T. Izaki, T. Kobayashi, J. Kusumoto, and A. Kanaya, "A creep life assessment method for boiler pipes using small punch creep test," International Journal of Pressure Vessels and Piping, vol. 86, no. 9, pp. 637-642, 2009.

[23] T. Massé and Y. Lejeail, "Creep behaviour and failure modelling of modified 9Cr1Mo steel," Nuclear Engineering and Design, vol. 246, pp. 220-232, 2012.

[24] T. Massé and Y. Lejeail, "Creep mechanical behaviour of modified 9Cr1Mo steel weldments: experimental analysis and modelling," Nuclear Engineering and Design, vol. 254, pp. 97110, 2013.

[25] J. Weber, A. Klenk, and M. Rieke, "A new method of strength calculation and lifetime prediction of pipe bends operating in the creep range," International Journal of Pressure Vessels and Piping, vol. 82, no. 2, pp. 77-84, 2005.

[26] J. Oldham and J. Abou-Hanna, "A numerical investigation of creep-fatigue life prediction utilizing hysteresis energy as a damage parameter," International Journal of Pressure Vessels and Piping, vol. 88, no. 4, pp. 149-157, 2011.

[27] C.-S. Oh, N.-H. Kim, Y.-J. Kim, C. Davies, K. Nikbin, and D. Dean, "Creep failure simulations of $316 \mathrm{H}$ at $550^{\circ} \mathrm{C}$. Part I. A method and validation," Engineering Fracture Mechanics, vol. 78, no. 17, pp. 2966-2977, 2011.

[28] N.-H. Kim, C.-S. Oh, Y.-J. Kim, C. M. Davies, K. Nikbin, and D. W. Dean, "Creep failure simulations of $316 \mathrm{H}$ at $550^{\circ} \mathrm{C}$ : part IIeffects of specimen geometry and loading mode," Engineering Fracture Mechanics, vol. 105, pp. 169-181, 2013.

[29] H.-T. Yao, F.-Z. Xuan, Z. Wang, and S.-T. Tu, "A review of creep analysis and design under multi-axial stress states," Nuclear Engineering and Design, vol. 237, no. 18, pp. 1969-1986, 2007.

[30] B. Lewis and L. Beckwith, "A unified approach to turbine blade life prediction," SAE Transactions, vol. 91, pp. 4496-4512, 1982.

[31] A. O. Abu, S. Eshati, P. Laskaridis, and R. Singh, "Aero-engine turbine blade life assessment using the Neu/Sehitoglu damage model," International Journal of Fatigue, vol. 61, pp. 160-169, 2014.

[32] G. Marahleh, A. R. I. Kheder, and H. F. Hamad, "Creep life prediction of service-exposed turbine blades," Materials Science and Engineering A, vol. 433, no. 1-2, pp. 305-309, 2006.

[33] L. Chen, Y. Liu, and L. Xie, "Power-exponent function model for low-cycle fatigue life prediction and its applications-part I: models and validations," International Journal of Fatigue, vol. 29, no. 1, pp. 1-9, 2007.

[34] L. Chen, Y. Liu, and L. Xie, "Power-exponent function model for low-cycle fatigue life prediction and its applicationspart II: life prediction of turbine blades under creep-fatigue interaction," International Journal of Fatigue, vol. 29, no. 1, pp. 10-19, 2007.

[35] J. A. Rodríguez, Y. El Hamzaoui, J. A. Hernández, J. C. García, J. E. Flores, and A. L. Tejeda, "The use of artificial neural network (ANN) for modeling the useful life of the failure assessment in blades of steam turbines," Engineering Failure Analysis, vol. 35, pp. 562-575, 2013.

[36] B. M. Schönbauer, S. E. Stanzl-Tschegg, A. Perlega et al., "Fatigue life estimation of pitted $12 \% \mathrm{Cr}$ steam turbine blade steel in different environments and at different stress ratios," International Journal of Fatigue, vol. 65, pp. 33-43, 2014.
[37] H. M. Tawancy and L. M. Al-Hadhrami, "Comparative performance of turbine blades used in power generation: damage vs. microstructure and superalloy composition selected for the application," Engineering Failure Analysis, vol. 46, pp. 76-91, 2014.

[38] H. C. Yu and X. R. Wu, Handbook of Aero-Engine Materials, Aviation Industry Press, Beijing, China, 2010, (Chinese).

[39] L. Li, Y. D. Song, and X. R. Huang, "Analysis on creep and creep life of rotors connecting bolts," Technology \& New Process, vol. 6, pp. 75-79, 2010 (Chinese).

[40] X. X. Liu, X. R. Zhang, X. J. Yan, and J. X. Nie, “The finite element analysis of HLCF life prediction for PM FGH95 based on damage mechanics," Journal of Aerospace Power, vol. 18, no. 1, pp. 101-108, 2003 (Chinese).

[41] L. Zhang, Research of fatigue failure on high-temperature parts based on damage mechanics [Ph.D. thesis], Beijing University of Aeronautics and Astronautics, 1995, (Chinese).

[42] R. D. Thulin and H. D. Singer, "NASA energy efficient engine high-pressure turbine detailed design report," CR-165608, 1984.

[43] J. N. Reddy and D. K. Gartling, The Finite Element Method in Heat Transfer and Fluid Dynamics, CRC Press, New York, NY, USA, 2000.

[44] C. L. Meng and S. Q. Rao, "Study on predict methods about creep break life of turbine blade," Journal of Beijing Technology and Bussiness University, vol. 20, pp. 52-54, 2002 (Chinese).

[45] R. W. Evans and B. Wilshire, Creep of Metals and Alloys, The Institute of Metals, London, UK, 1985.

[46] S.-G. Tian, Z.-G. Zhao, L.-Q. Chen et al., "Influence of direct aged treatment on creep behaviors of hot continuous rolling GH4169 superalloy," Journal of Aeronautical Materials, vol. 30, no. 5, pp. 14-18, 2010 (Chinese). 


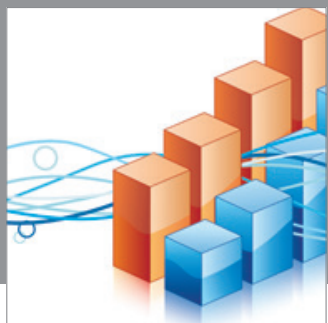

Advances in

Operations Research

mansans

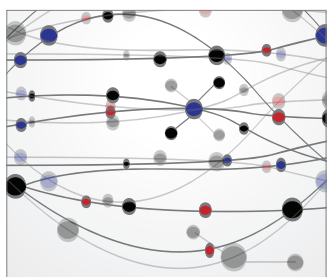

The Scientific World Journal
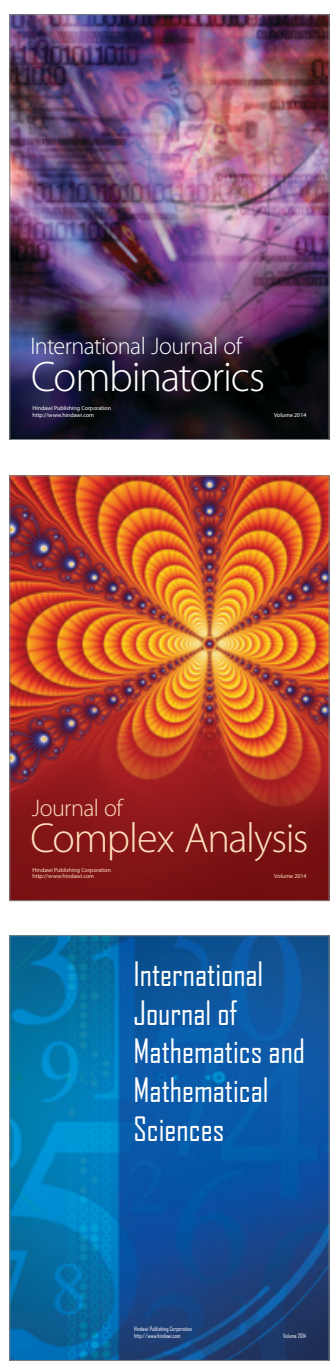
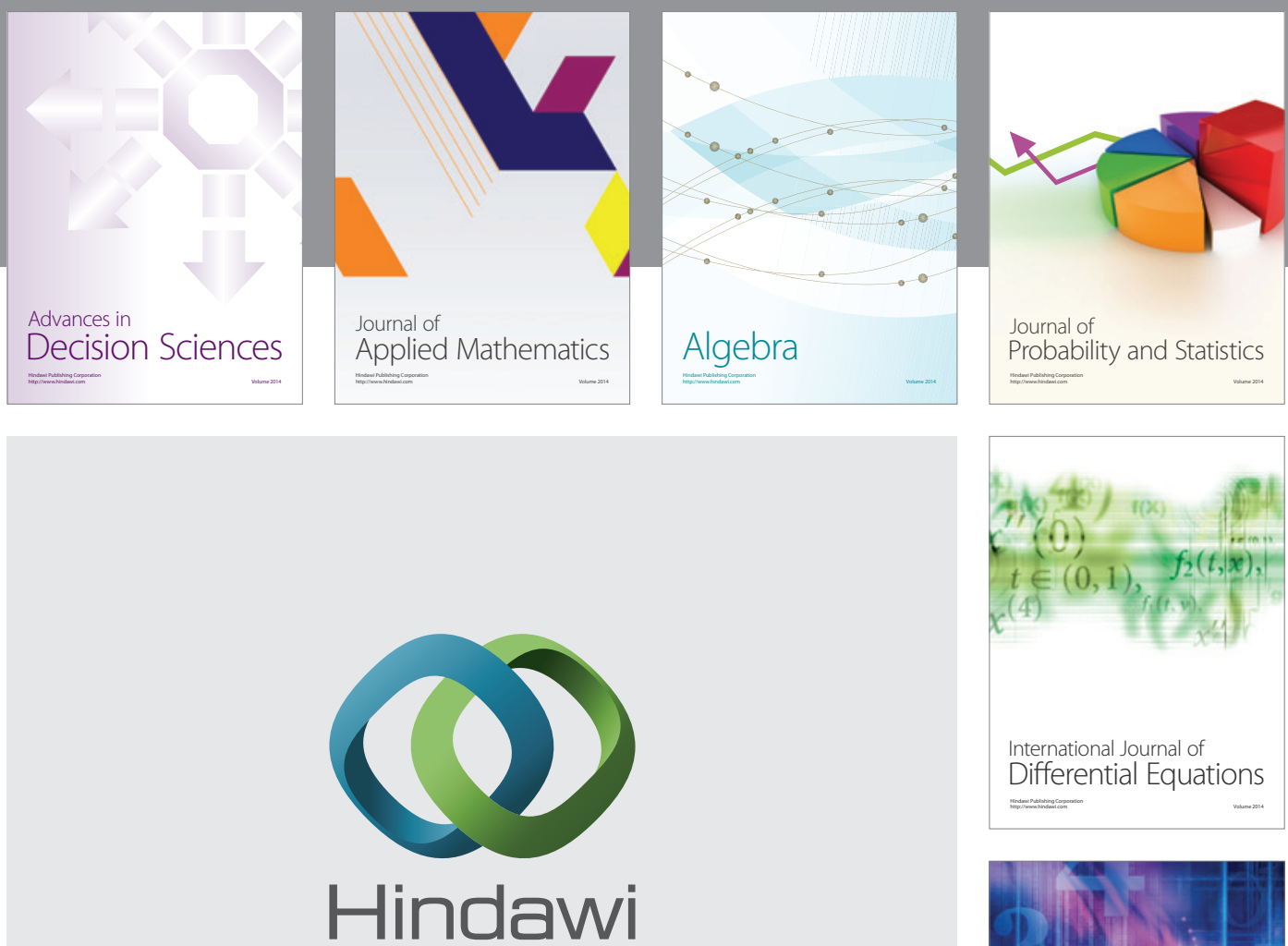

Submit your manuscripts at http://www.hindawi.com
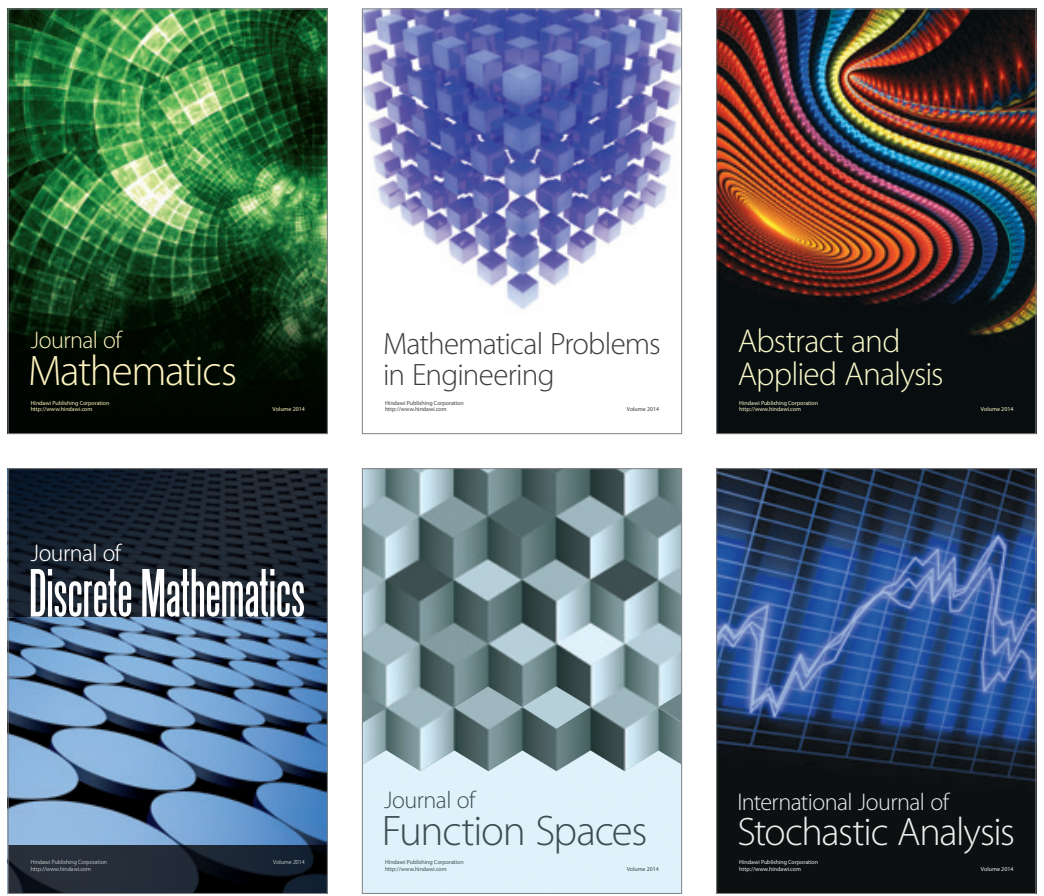

Journal of

Function Spaces

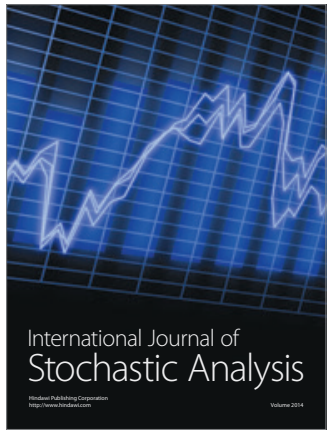

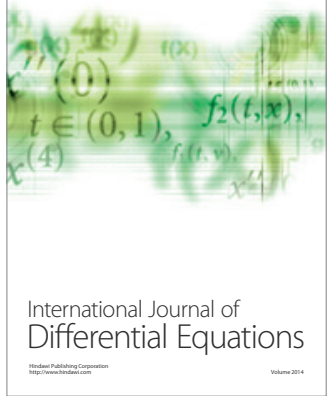
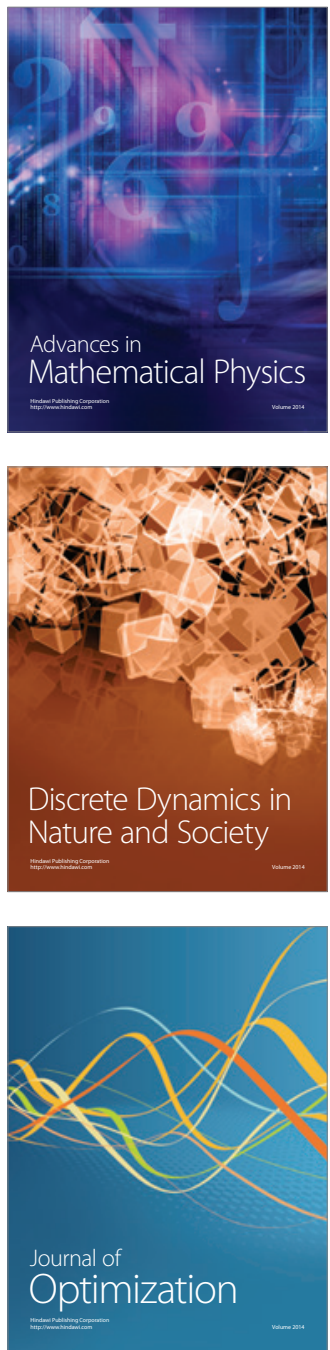